\title{
PERFORMANCE COMPARISON OF TWO TYPES OF TECHNOLOGIES ASSOCIATED WITH A POSITIVE ENERGY BUILDING: A REVERSIBLE HEAT PUMP/ORC UNIT AND A HEAT PUMP COUPLED WITH PV PANELS
}

\author{
Olivier Dumont ${ }^{1}$, Carolina Carmo ${ }^{2}$, François Randaxhe ${ }^{1}$, Sylvain Quoilin ${ }^{1}$ and Vincent Lemort ${ }^{1}$ \\ ${ }^{1}$ Aerospace and Mechanical Engineering Department, Faculty of Applied Sciences, University of \\ Liege (Belgium) \\ ${ }^{2}$ Department of Energy Technology, Aalborg University, Aalborg (Denmark)
}

\begin{abstract}
To achieve the 20-20-20 targets in 2020 and the European objectives in the longer term, it is imperative to drastically reduce greenhouse gas emissions from the residential building sector. In this context, the development of Positive Energy Buildings (PEB) is promising. This work compares the annual performance of two competing systems. First, a conventional solution, consisting of a passive house coupled with a water to water heat pump and photovoltaic panels (HP/PV). On the other hand, a passive house with a solar thermal roof combined with a reversible heat pump unit / organic Rankine cycle (HP/ORC). Both systems are designed for a maximum net electrical output of $5.29 \mathrm{~kW}$. Dynamic simulations are performed using the Dymola software. The net annual electrical production (considering electricity consumed to fulfil the thermal load of the building) is $667 \mathrm{kWh}$ for the reversible HP/ORC system and $3835 \mathrm{kWh}$ for the HP/PV system in the basic Danish study case. Following that, a study of influence with different climates is performed and some guidelines are deduced to select optimum study cases where the HP/ORC system could become more competitive than the HP/PV classical solution.
\end{abstract}

Keywords: Reversible heat pump/organic Rankine cycle unit, Photovoltaics panels, Positive Energy Building, annual simulation, economic analysis.

\section{Introduction}

Positive Energy Buildings have been increasingly investigated recently. Moreover, from 2019, all new buildings will have to produce from renewable energy has much as they consume on an annual basis (European parliament, 2010). The objective of this paper is to assess an innovative technology to obtain a positive energy building and compare it with a conventional HP/PV solution. The innovative technology solution consists in coupling a reversible heat pump/organic Rankine cycle unit (HP/ORC) with a passive building, a solar roof and a horizontal ground heat exchanger (Quoilin et al, 2015). This system is flexible because of the reversibility of the heat pump (HP) which can also run in organic Rankine cycle mode (ORC) to generate electricity (Fig. 2). There are, in fact, three possible modes of operation. First, the heat pump mode can cover the thermal demand of the house (includes domestic hot water - DHW - and floor heating - FH) when weather conditions are unfavourable, for example in winter. But, when the sunlight is sufficient, the heat produced by the solar roof is directly used to charge the storage to supply DHW and FH (direct heating mode - DH). Finally, when the storage is fully charged, the excess heat produced by the solar roof generates electricity through the ORC cycle. The HP/ORC reversible system has been studied for the first time in 2011 (Schimpf et al, 2011). This study showed the economic benefits in the particular case of a house with geothermal borehole and a solar collector of modest size $\left(12 \mathrm{~m}^{2}\right)$. Thereafter, the passive house concept coupled with a solar roof large $\left(138.8 \mathrm{~m}^{2}\right)$ and coupled with a horizontal ground heat exchanger (300 m long) was patented by the company Innogie (Innogie, 2013). Following this, an optimal design (Quoilin et al, 2015), followed by an experimental campaign (Dumont et al, 2015) have demonstrated the feasibility of the system. The nominal power generation ORC mode is equal to $5.29 \mathrm{~kW}$ with an efficiency of $7 \%$, while the HP mode presents a thermal power condenser of $13 \mathrm{~kW}$ with a nominal coefficient of performance (COP) of 4.2. 


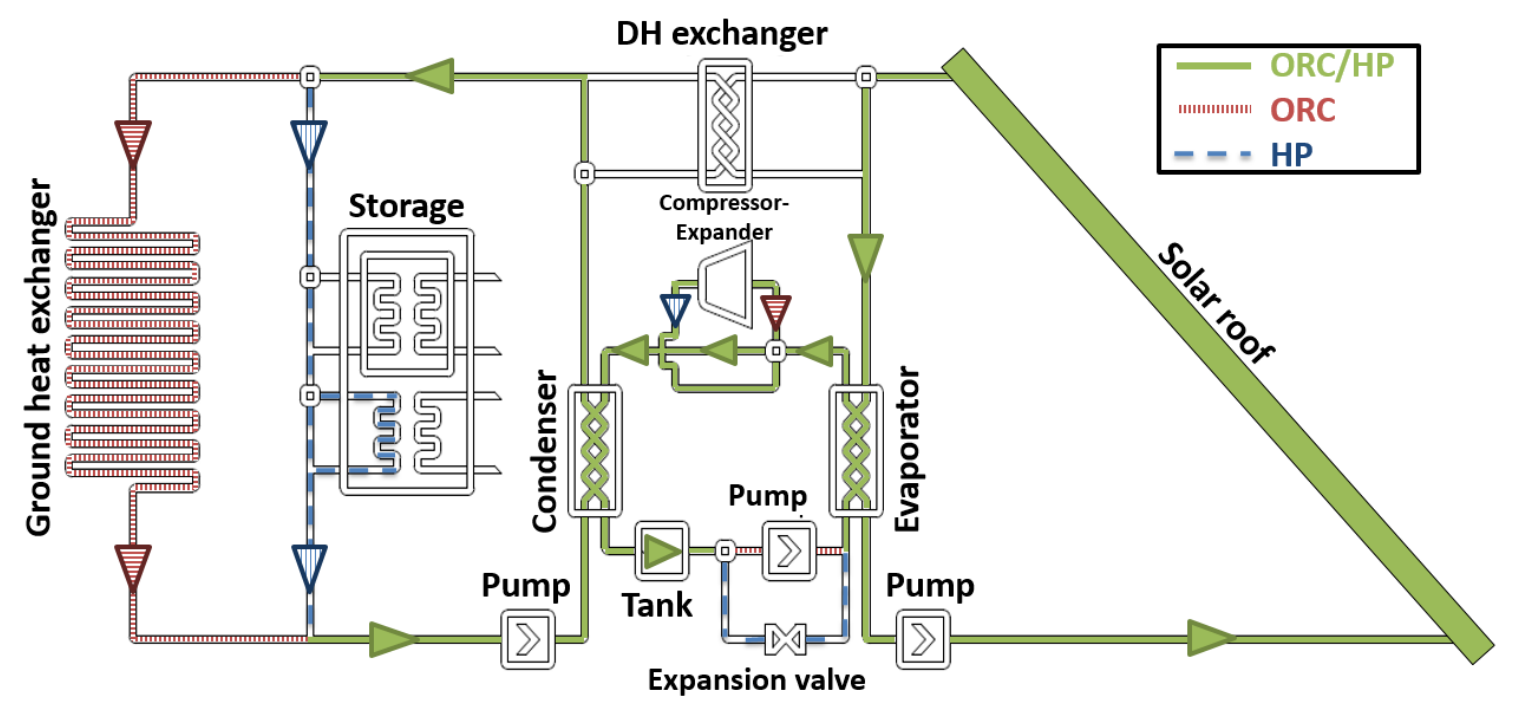

Fig. 1: Scheme of the global system showing the three operating modes (organic Rankine Cycle (ORC), heat pump (HP) and direct heating (DH))

\section{Description of the model}

The model is simulated with Dymola/modelica software coupled with Thermocycle (Quoilin et al, 2014) libraries and CoolProp (CoolProp, 2015). The global model with the passive house, the reversible HP/ORC unit, the solar roof, the horizontal ground heat exchanger and the thermal heat storage has been extensively described in a former paper (Dumont et al, 2014). This section briefly summarizes each sub-model.

\subsection{Sub-models}

- The reversible HP/ORC unit is modelled trough validated semi-empirical models based on experimentation (Dumont et al, 2015).

- The storage model (Heat Storage Water Heater) comes from the Thermocycle library (Quoilin et al, 2014).

- The solar roof is modelled with Klein's equation (Klein, 1975).

- The house model consider 5 zones based on the real Danish house. Solar gains, air infiltration, occupancy behaviour in terms of internal gain and domestic hot water consumption are taken into account.

More details are provided for each sub-model of the reversible HP/ORC system coupled with the passive house in (Dumont et al, 2014).

The performance of this system is compared with a mature system to get a Positive Energy Building (PEB), a water to water heat pump coupled with PV panels (HP/PV). The PV panels are modelled based on a detailed model (De Soto et al, 2006). The area of the PV panels is determined in a way to get the same peak electrical production in summer nominal conditions ( $5290 \mathrm{~W}$ for $44 \mathrm{~m}^{2}$ ). The heat pump, the building model, the occupant behaviour are all fixed in the same way as for the reversible HP/ORC unit.

\subsection{Global model}

The inputs of the global model are the meteorological data (in terms of outdoor temperature and direct normal radiation) and occupant behaviour in terms of electrical consumption, internal gains and domestic hot water consumption. The control strategy to select the operating mode is based on the following idea: Insuring the thermal comfort inside the building while maximizing the net electrical production. 


\section{Results}

Results from typical days of the year with mode changes are detailed in a former paper (Dumont et al, 2014). This section aims at evaluating the annual performance of the system.

\subsection{Performance criterions}

- Gross electrical production [kWh]: annual electrical production of the ORC (or of the PV panels in the case of the HP/PV).

- Net electrical production [kWh]: annual electrical production of the ORC (or of the PV panels in the case of the HP/PV) minus the heat pump consumption and the non-HVAC consumption.

- Running benefits $[€]$, evaluated following Danish electricity market (Eq. 1). $C_{r}$ is the retail price of electricity on the grid [€/kWh], $C_{r, H P}$ is the retail price for heat pump systems $[€ / \mathrm{kWh}]$ and $C_{b b}$ is the buy-back tarif of electricity to the grid [€/kWh]. $C_{x}$ is equal to $C_{b b}$ if electrical production is higher than the electrical consumption (non-HVAC) and equal to $C_{r}$ in the opposite case. $k W_{O R C}$ is the ORC electrical power [kW], $k W_{\text {cons }, l-a}$ is the electrical consumption (non-HVAC) et $k W_{H P}$ is the heat pump power consumption. Tariffs are provided from real data (Energinet, 2015).

$$
B=\int_{0}^{t}\left(C_{x}\left(k W_{O R C}-k W_{c o n s, l-a}\right)-C_{r, H P} \cdot k W_{H P}\right) \cdot d t
$$

- Self-production rate $\left(\gamma_{S}\right)$, which is the fraction of the gross production consumed directly in the building (eq. 2).

$$
\gamma_{S}=\frac{\sum \min \left(W_{\text {cons } \left., W_{\text {prod }}\right)}\right.}{\sum W_{\text {prod }}}
$$

- Self-consumption rate $\left(\gamma_{d}\right)$, which is the fraction of building electrical consumption produced by the gross electrical production (eq. 3).

$$
\gamma_{D}=\frac{\sum \min \left(W_{\text {cons. }} W_{\text {prod }}\right)}{\sum W_{\text {cons. }}}
$$

\subsection{Basic case}

The annual performance comparison is performed between the HP/ORC system and the HP/PV system in the case of the real house located in Denmark (500 litres storage and $1491 \mathrm{kWh}$ of lightning and appliances electrical consumption) in Tab. 1. First, the heat pump electrical consumption is $45 \%$ higher in the case of the HP/PV because this system does not benefit from the thermal heat furnished by the direct heating mode $(1394 \mathrm{kWh})$. Also, the gross electrical production is lower in the case of the HP/ORC system. This is explained by the rather constant efficiency of the PV panels while the ORC efficiency (and solar roof efficiency) are very largely affected by part load conditions (low solar irradiation, low outdoor temperature).

Tab. 1: Comparison of the annual performance between the reversible heat pump/organic Rankine cycle unit (HP/ORC) and the PV panels coupled with the heat pump (PV/HP)

\begin{tabular}{|c|c|c|}
\hline System & HP/ORC & HP/PV \\
\hline Non HVAC electrical consumption $[\mathrm{kWh}]$ & \multicolumn{2}{|c|}{1491} \\
\hline Heat pump consumption $[\mathrm{kWh}]$ & 812 & 1185 \\
\hline Gross electrical production $[\mathrm{kWh}]$ & 2970 & 6511 \\
\hline Net electrical production $[\mathrm{kWh}]$ & 667 & 3835 \\
\hline Thermal load (domestic hot water \& floor heating) $[\mathrm{kWh}]$ & \multicolumn{2}{|c|}{4403} \\
\hline Thermal energy provided by direct heating $[\mathrm{kWh}]$ & 1394 & 0 \\
\hline Running benefits [€] & -78 & 494 \\
\hline Self-production rate [-] & 8.9 & 9.1 \\
\hline Self-consumption rate $[-]$ & 9.2 & 39 \\
\hline
\end{tabular}


Following this, it is logical that the net electrical production and the running benefits are higher in the case of the HP/PV system. Furthermore, the self-consumption and self-production rates are significantly lower in the case of the HP/ORC system. Fig. 2 allows to understand this. The peak electricity demand between 6 p.m. and 7 p.m. is covered by the PV panels while the ORC stop working a little bit before 6 p.m.

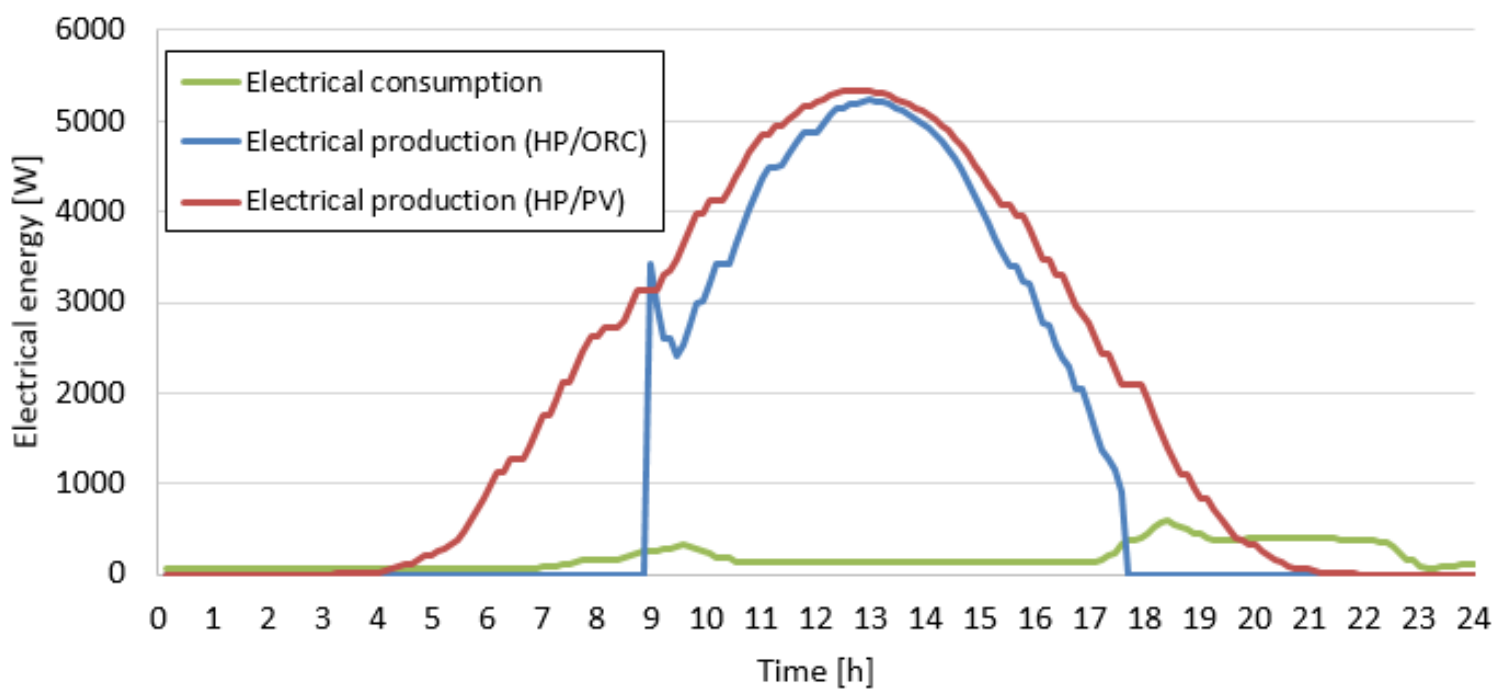

Fig. 2: Hourly electrical production and consumption for a typical summer day

\subsection{Influence of the climate}

The basic case has shown higher performances for the HP/PV system. It is also interesting to study the influence of the climate regarding the evolution of the performance of both systems. Fig. 3 presents the gross electrical production and the heat pump electrical consumption for 5 typical climate in Europe (from north to south). First, the same conclusion as stated in section 3.2 can be deduced: the heat pump consumption is significantly lower with the HP/ORC system thanks to the direct heating mode. In southernmost locations, the heat pump is not even necessary anymore to fulfil the heat requirements of the buildings for this system. This means that in location close to Roma and Palermo, the use of a reversible heat pump/organic Rankine cycle does not make any sense. Also, the ORC gross production increase more than the PV panels production because the ORC system works more and more often closer to nominal conditions in southernmost locations. The direct heating heat (not shown in Fig. 3) presents a maximum in Torino. This is explained by the fact that if the weather is too cold, the roof is not warm enough to heat the storage but if the weather is too warm, the thermal load is lower. 


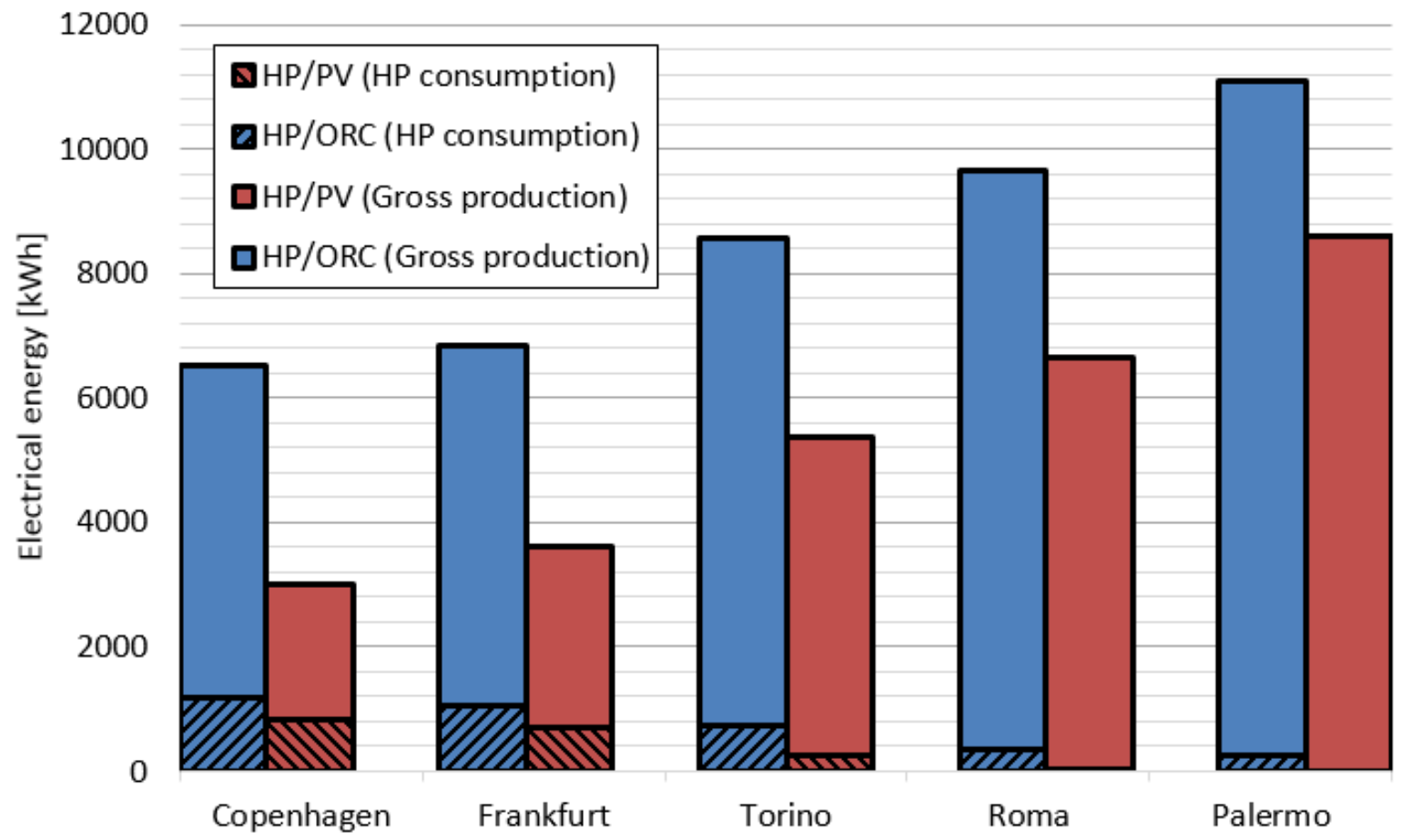

Fig. 3: Comparison of the gross electrical production and the heat pump electrical consumption for both systems (HP/ORC and HP/PV) for 5 typical climates in Europe.

\subsection{Analysis of results}

Results in the basic case and with five different location have shown that the HP/PV system present better overall performance in terms of net electrical production, running benefits and matching of electricity demand and consumption.

The HP/ORC system presents two advantages. On the one hand, the investment costs are rather low since the cost are very close to a classical heat pump (addition of a pump and a four way valve for the reversibility in ORC mode). On the other hand, the electrical consumption is lower for the HP/ORC system thanks to the heat provided by the roof (Direct Heating). This is a non-negligible advantage of the system since it can reduce electricity consumption during peak of electricity.

This study shows that the HP/ORC system is more efficient in location close to Torino thanks to the direct heating mode. The direct heating mode does not reduce ORC running hour because it works at much lower roof temperatures. Therefore, cases where thermal load are higher could be very interesting and make the HP/ORC system more competitive than the HP/PV system. Some examples with high thermal load could be large buildings, buildings with poor insulation, building with high domestic hot water needs (sports hall, swimming pool...

\section{Conclusion}

This paper compares two systems that allow getting a Positive Energy Building: a reversible HP/ORC unit and a $\mathrm{HP} / \mathrm{PV}$ system. A dynamic model is developed and exploited to analyse annual performance. It has been shown that in the basic study case (Denmark), the HP/PV system is more profitable. Following this, a study of influence with five different typical European climates has shown that mid-Europe is an optimal location for the HP/ORC system. But, still, the HP/PV system performs better.

This lead to study more influence parameters. Since the direct heating mode is a significant advantage of the HP/ORC system, this could be exploited in cases where thermal load of the building is higher. This will be studied in future works. 


\section{Nomenclature}

$\begin{array}{ll}\text { B } & \text { Running benefits }[€] \\ \text { DH } & \text { Direct Heating } \\ \text { DHW } & \text { Domestic hot water } \\ \gamma \mathrm{s} & \text { Self-production rate }[-] \\ \gamma \mathrm{d} & \text { Self-consumption rate [-] } \\ \text { FH } & \text { Floor-heating } \\ \text { HP } & \text { Heat Pump } \\ \text { ORC } & \text { Organic Rankine Cycle } \\ \text { PV } & \text { Photovoltaics panels } \\ \text { HP/ORC } & \text { Reversible HP/ORC system } \\ \text { HP/PV } & \text { PV panels coupled with a HP }\end{array}$

\section{References}

Coolprop library, 2015. http://www.coolprop.org, consulted the 5th of January 2015.

De Soto, W., Klein, S. A., Beckman, A., 2006. Improvement and validation of a model for photovoltaic array performance, Solar Energy, 80, 78-88.

Dumont, O., Carmo, C., Randaxhe, F., Quoilin, S., Lemort, V., 2014. Simulation of a passive house coupled with a heat pump/organic Rankine cycle reversible unit, 9th International Conference on System Simulation in Buildings.

Dumont, O., Quoilin, S., Lemort, V., 2015. Experimental investigation of a reversible heat pump / organic Rankine cycle unit designed to be coupled with a passive house to get a Net Zero Energy Building, International Journal of Refrigeration, doi:10.1016/j.ijrefrig.2015.03.008.

Energifnet, http://energinet.dk/DA/El/Solceller/Har-du-solceller/Sider/Pristillaeg.aspx, consulted the 5th of january 2015.

European parliament, 2010. Directive 2010/31/EU of the European parliament and of the council of 19 May 2010 on the energy performance of buildings, http://eurlex.europa.eu/LexUriServ/LexUriServ.do?uri=OJ:L:2010:153:0013:0035:EN:PDF

Innogie ApS, 2013. Thermal solar absorber system generating heat and electricity, United States Patent Application Publication, US 2013/025778 A.

Klein, S. A., 1975. Calculation of flat-plate loss coefficient, Solar Energy, 17.

Quoilin, S., Dumont, O., Harley, K., Lemort, V., 2015. Design, modeling and performance optimization of a reversible Heat Pump / Organic Rankine Cycle prototype. ASME Journal of Engineering for Gas Turbines and Power, doi:10.1115/1.4031004

Quoilin, S., Desideri, A., Wronski, J., Bell, I., Lemort, V., 2014. ThermoCycle: A Modelica library for the simulation of thermodynamic systems, 10th International Modelica Conference, Modelica Association., 10.3384/ECP14096683, Lund.

Schimpf, S., Uitz, K., Span, R., 2011. Simulation of a solar assisted combined heat pump-organic Rankine cycle system, World renewable Energy Congress 